\title{
Key drivers of ecosystem recovery after disturbance in a neotropical forest
}

\author{
Long-term lessons from the Paracou experiment, French Guiana \\ Bruno Hérault ${ }^{1,2^{*}}$ (1) and Camille Piponiot ${ }^{3}$
}

\begin{abstract}
Background: Natural disturbance is a fundamental component of the functioning of tropical rainforests let to natural dynamics, with tree mortality the driving force of forest renewal. With ongoing global (i.e. land-use and climate) changes, tropical forests are currently facing deep and rapid modifications in disturbance regimes that may hamper their recovering capacity so that developing robust predictive model able to predict ecosystem resilience and recovery becomes of primary importance for decision-making: (i) Do regenerating forests recover faster than mature forests given the same level of disturbance? (ii) Is the local topography an important predictor of the post-disturbance forest trajectories? (iii) Is the community functional composition, assessed with community weighted-mean functional traits, a good predictor of carbon stock recovery? (iv) How important is the climate stress (seasonal drought and/or soil water saturation) in shaping the recovery trajectory?
\end{abstract}

Methods: Paracou is a large scale forest disturbance experiment set up in 1984 with nine 6.25 ha plots spanning on a large disturbance gradient where 15 to $60 \%$ of the initial forest ecosystem biomass were removed. More than 70,000 trees belonging to ca. 700 tree species have then been censused every 2 years up today. Using this unique dataset, we aim at deciphering the endogenous (forest structure and composition) and exogenous (local environment and climate stress) drivers of ecosystem recovery in time. To do so, we disentangle carbon recovery into demographic processes (recruitment, growth, mortality fluxes) and cohorts (recruited trees, survivors).

Results: Variations in the pre-disturbance forest structure or in local environment do not shape significantly the ecosystem recovery rates. Variations in the pre-disturbance forest composition and in the post-disturbance climate significantly change the forest recovery trajectory. Pioneer-rich forests have slower recovery rates than assemblages of late-successional species. Soil water saturation during the wet season strongly impedes ecosystem recovery but not seasonal drought. From a sensitivity analysis, we highlight the pre-disturbance forest composition and the post-disturbance climate conditions as the primary factors controlling the recovery trajectory.

Conclusions: Highly-disturbed forests and secondary forests because they are composed of a lot of pioneer species will be less able to cope with new disturbance. In the context of increasing tree mortality due to both (i) severe droughts imputable to climate change and (ii) human-induced perturbations, tropical forest management should focus on reducing disturbances by developing Reduced Impact Logging techniques.

Keywords: Ecosystem modeling, Tropical forests, Carbon fluxes, Ecological resilience, Climate change, Amazonia

*Correspondence: bruno.herault@cirad.fr

${ }^{1}$ Cirad, UMR EcoFoG (AgroParistech, CNRS, Inra, Université des Antilles,

Université de la Guyane), Campus Agronomique, 97310 Kourou, French

Guiana, France

${ }^{2}$ INPHB (Institut National Polytechnique Félix Houphouët Boigny),

Yamoussoukro, Ivory Coast

Full list of author information is available at the end of the article

\section{Springer Open}

(c) The Author(s). 2018 Open Access This article is distributed under the terms of the Creative Commons Attribution 4.0 International License (http://creativecommons.org/licenses/by/4.0/), which permits unrestricted use, distribution, and reproduction in any medium, provided you give appropriate credit to the original author(s) and the source, provide a link to the Creative Commons license, and indicate if changes were made. 


\section{Background}

In tropical forests, natural disturbances caused by the death of one or more trees are the dominant forms of forest regeneration as the creation of canopy openings continuously reshapes forest structure (Goulamoussène et al. 2017). The immediate increase in light intensity allows the sunlight to penetrate the understorey (Goulamoussène et al. 2016) and light-demanding trees (Denslow et al. 1998) to establish and grow, thus contributing to the maintenance of biodiversity that shapes forest functionning (Liang et al. 2016). Another effect of canopy gaps is the local modification of the forest nutrient balance due to the large amounts of dead leaves and wood that decompose and mineralize (Brokaw and Busing 2000) and that shapes in turn the smallscale spatial variations in forest carbon balance (Feeley et al. 2007; Guitet et al. 2015; Rutishauser et al. 2010). In this way, the natural disturbance regime is a fundamental component of the functioning of tropical forests (Sheil and Burslem 2003).

With ongoing global (i.e land-use and climate) changes, tropical forests are currently facing deep and rapid changes in disturbance regimes that may hamper their recovering capacity (Hérault and Gourlet-Fleury 2016; Brienen et al. 2015). Human-induced disturbances may encompass a wide range of perturbations from longlasting ones such as land-cover changes for industrial agriculture, slash-and-burn agriculture or mining (Dezécache et al. 2017a,b) to more insiduous modifications such as selective logging that may not affect the forest cover but modify forest functioning (Rutishauser et al. 2015). An even more insiduous perturbation is climate change (Hérault and Gourlet-Fleury 2016). Global circulation models have shown high probabilities of significant precipitation decrease for tropical areas with a risk of transition from short-dry-season rainforest to longdry- season savannah ecosystems (Davidson et al. 2012). For instance, after the intense 2005 drought in Amazonia, the forest suffered an additional mortality, leading to a huge loss of live biomass (Phillips et al. 2009) with similar mortality events observed in Panama (Condit 1995), in China (Tan et al. 2013) or in South-East Asia (Slik 2004).

To our opinion, the drivers of the post-disturbance system trajectory may first be defined based on their origin: endogeneous and exogeneous. (1) Endogenous drivers refer to the internal properties of the system that may influence its post-disturbance behavior. A significant example for ecological systems is the species composition that partially informs on the immediate potential of the system to recover after disturbance. In that respect, the species identity is far less important than the functional signature of the species assemblage (Kunstler et al. 2016): for example, an assemblage of light- demanding species will respond differently to disturbance from an assemblage of shade-tolerant understorey species (Herault et al. 2010). Structural characteristics of the pre-disturbance species community (stem density, average size, live biomass and so on) may also be of primary importance because they are core indicators of the silvigenetic stage of the forest (Pillet et al. 2017). (2) Exogenous drivers refer to external constraints or forces that limit the possible system trajectories. They can be grouped into two broad categories: drivers that vary in space and those that vary in time. The local environment, i.e. the physical characteristics of the abiotic environment, is here defined in space but not in time. On the contrary, external conditions such as climatic stress are here considered to vary in time but not in space.

This study draws upon the long-term disturbance experiment of Paracou, French Guiana, to develop a modeling approach in order to mechanistically link the endo- and exogenous ecosystem drivers to the ecosystem recovery trajectory after disturbance. More specifically, we ask the following questions: (i) Do regenerating forests recover faster than mature forests given the same level of disturbance? (ii) Is the local topography an important predictor of the forest recovery rates? (iii) Is the community functional composition, assessed with community weighted-mean functional traits, a good predictor of carbon stock recovery? (iv) How important is the climate stress (drought and/or soil water saturation) to shape the rate of carbon recovery? To do so, we partition the contributions to post-disturbance ACS (Aboveground Carbon Stock) gain (from growth and recruitment of trees sup 10 $\mathrm{cm}$ DBH) and ACS loss (from mortality) of survivors and recruited trees to detect the main drivers and patterns of ACS recovery after disturbance. We model the trajectory of those post-disturbance ACS changes (Piponiot et al. 2016b) in a comprehensive Bayesian framework. We then quantify the effect of (i) endogeneous (forest structure and composition) and (ii) exogeneous (local environment and climate stress) drivers on the rates at which post-disturbance ACS changes converge to a theoretical steady state. Summing these ACS changes over time gives the net post-disturbance rate of ACS accumulation, an indicator of the ecosystem recovery rate. Disentangling ACS recovery with a demographic processbased approach, i.e. by segregating ACS changes into cohorts (survivors and recruits) and demographic processes (growth, recruitment, mortality), as opposed to an all-in-one model in which only the ecosystem net ACS change is modeled without examination of demographic processes, has been shown to be essential to reveal mechanisms underlying ACS responses to disturbance and to make more robust predictions of ACS recovery (Piponiot et al. 2016b). 


\section{Methods \\ Study site}

The study was conducted at the Paracou experimental site $\left(5^{\circ} 18^{\prime} \mathrm{N}, 52^{\circ} 55^{\prime} \mathrm{W}\right)$, a lowland tropical rain forest near Sinnamary, French Guiana. The site receives nearly twothirds of the annual $3041 \mathrm{~mm}$ of precipitation between mid-March and mid-June, and $<50 \mathrm{~mm}$ per month in September and October (Wagner et al. 2011). More than 700 woody species attaining $2 \mathrm{~cm} \mathrm{DBH}$ (diameter at breast height) have been described at the site, with $150-210$ species of trees $>10 \mathrm{~cm}$ DBH per hectare. The floristic composition is typical of Guianan rainforests with dominant families including Leguminoseae, Chrysobalanaceae, Lecythidaceae, Sapotaceae and Burseraceae (Guitet et al. 2014). In 1984, nine 6.25 ha plots, each one divided into 4 subplots of 1.56 ha each, were established for a complete inventory of all trees $>10 \mathrm{~cm}$ DBH. From October 1986 to May 1987, the plots underwent three disturbance treatments (details in Table 1 and in (Blanc et al. 2009)).

\section{Input data}

Aboveground Carbon Stock (ACS) computation In all plots, diameter at breast height $(\mathrm{DBH})$ of trees $>10 \mathrm{~cm}$ DBH were measured every two years from 1982 to 2016 resulting in 18 forest censuses. Trees were identified to the lowest taxonomic level. To get wood density, we applied the following standardized protocol: (i) tree identified to the species level were assigned the corresponding wood specific gravity value from the Global Wood Density Database (GWDD) (Chave et al. 2009); (ii) trees identified to the genus level were assigned a genus-average wood density and (iii) trees with no botanical identification or that were not in the GWDD were assigned the subplot-average wood density. The aboveground biomass (AGB) was estimated taking all uncertainties into account using the BIOMASS package (Réjou-Méchain et al. 2017). Biomass was assumed to be $47 \%$ carbon.

Disturbance intensity After disturbance, the subplot's ACS decreases rapidly until it reaches its minimum value acs $_{\text {min }}$ a few years later. This transition point determines the beginning of the recovery period. The difference between the averaged pre-disturbance ACS acspre and this post-logging minimum value $a c s_{\min }$ reached at time $t=t_{\text {min }}$ defines the disturbance intensity DIST. In other words, the disturbance intensity is defined as the amount of aboveground carbon lost in the forest ecosystem during the first years during and after the disturbance.

Structure drivers The pre-disturbance forest structure was assessed with three variables: the stem density $S_{N}$ (from 483 to 727 ind.ha ${ }^{-1}$ ) and the basal area $S_{B A}$ (from 27 to $36 \mathrm{~m}^{2} \cdot \mathrm{ha}^{-1}$ ) of subplot $j$ at $t_{\text {pre }}$, the year preceding the disturbance experiment.

Environment drivers Three environmental drivers were selected from a preliminary exploratory analysis to represent independent source of variation in the local forest physical conditions: the proportion of bottom-lands $E_{\text {BOTTOM }}$, the average topographical slopes of the plot $E_{S L O P E}$ and the standard deviation, i.e the heterogeneity, of the altitudinal distribution $E_{H E T E}$.

Composition drivers The pre-disturbance forest composition was assessed in a functional trait space to avoid local taxonomic variations in tree assemblages that are of little importance for forest functioning. The four chosen orthogonal traits $F T$ represent key dimensions of the tree functional strategy (Baraloto et al. 2010): wood density $T_{W D}$, seed mass $T_{S E E D}$, specific leaf area $T_{S L A}$ and maximum diameter $T_{D B H 95}$ estimated as the 95 th percentile of the species DBH distribution in the Guyafor database. The community weighted means of these functional traits were calculated the year preceding the disturbance experiment.

Climate drivers We considered two main sources of climate stress: soil drought $C_{D R O U G H T}$ and soil water saturation $C_{W A T E R}$. These variables were quantified using a water balance model, developed and calibrated in Paracou (Wagner et al. 2011), that was run using precipitation and evapotranspiration as inputs over the 1982-2016 time period. $C_{D R O U G H T}$ was estimated as the number of days with REW, Relative Extractable Water, below 0.4 while the number of days with REW equal to 1 , the soil is

Table 1 Disturbance treatments (T1, T2, T3) implemented on the Paracou plots in 1986-1987

\begin{tabular}{|c|c|c|c|c|}
\hline & Timber logging & Fuelwood logging & Thinning & $\%$ ACS loss \\
\hline$\overline{\mathrm{T} 1}$ & $\mathrm{DBH} \geq 50 \mathrm{~cm}$, mean of 10 trees $\cdot \mathrm{ha}^{-1}$ & - & - & {$[12-33 \%]$} \\
\hline $\mathrm{T} 2$ & $\mathrm{DBH} \geq 50 \mathrm{~cm}$, mean of 10 trees $\cdot \mathrm{ha}^{-1}$ & - & $\begin{array}{l}\mathrm{DBH} \geq 40 \mathrm{~cm} \text {, all non-valuable } \\
\text { species, mean of } 30 \text { trees } \cdot \mathrm{ha}^{-1}\end{array}$ & {$[33-56 \%]$} \\
\hline T3 & $\mathrm{DBH} \geq 50 \mathrm{~cm}$, mean of 10 trees $\cdot \mathrm{ha}^{-1}$ & $\begin{array}{l}40 \mathrm{~cm} \leq \mathrm{DBH} \leq 50 \mathrm{~cm} \text {, all non- } \\
\text { valuable species, mean of } 20 \\
\text { trees.ha } \mathrm{ha}^{-1}\end{array}$ & $\begin{array}{l}\mathrm{DBH} \geq 40 \mathrm{~cm} \text {, all non-valuable } \\
\text { species, mean of } 15 \text { trees } \cdot \mathrm{ha}^{-1}\end{array}$ & {$[35-66 \%]$} \\
\hline
\end{tabular}

The percentage of Aboveground Carbon Stock loss (\% ACS loss) is defined as the difference between the pre-disturbance ACS and its minimum value reached during the 4 years after the disturbance treatments 
full of water, defined $C_{W A T E R}$. These two covariates were computed between 2 consecutive censuses and then standardized at a yearly time-step.

\section{Modeling strategy}

We define two cohorts of trees. First, recruits are all the trees $(>10 \mathrm{~cm} \mathrm{DBH})$ that have been recruited since the perturbation. Trees that, for a given census, first went through the $10 \mathrm{~cm} \mathrm{DBH}$ are called new recruits. Thereafter, they are called, for the following censuses, recruits and may grow or may eventually die between 2 censuses. Second, survivors are trees that were present in the forest before the disturbance and that survived the disturbance event.

For each subplot $j$ and census $k$, with $t_{k}$ the time since the beginning of the recovery period, we thus define 5 ACS changes : new recruits' ACS $\left(R r_{j, k}\right)$ is the ACS of all trees $<10 \mathrm{~cm} \mathrm{DBH}$ at $t_{k-1}$ and $\geq 10 \mathrm{~cm} \mathrm{DBH}$ at $t_{k}$; recruits' ACS growth $\left(R g_{j, k}\right)$ is the ACS increment of living recruits between $t_{k-1}$ and $t_{k}$; recruits' ACS loss $\left(R l_{j, k}\right)$ is the ACS in recruits that die between $t_{k-1}$ and $t_{k}$; survivors' ACS growth $\left(S g_{j, k}\right)$ is the ACS increment of living survivors between $t_{k-1}$ and $t_{k}$; survivors' ACS loss $\left(S l_{j, k}\right)$ is the ACS of survivors that die between $t_{k-1}$ and $t_{k}$. ACS changes are subject to large stochastic variation over time: because we are less interested in year-to-year variations than in long-term ACS trajectories, we modeled the cumulative ACS changes over time. Cumulative ACS changes $\left(\mathrm{Mg} \mathrm{C} \cdot \mathrm{ha}^{-1}\right)$ were defined as follows:

$$
\text { change }_{j, k}=\sum_{m=0}^{k}\left(\text { Change }_{j, m} \times\left(t_{k}-t_{k-1}\right)\right)
$$

where $j$ is the subplot, $k$ is the census number, $t_{k}$ the time since $t_{0}(\mathrm{yr})$ and Change is the annual ACS change $\left(\mathrm{Mg} \mathrm{C} \cdot \mathrm{ha}^{-1} \cdot y r^{-1}\right)$, either recruits' ACS $(R r)$, recruits' ACS growth $(R g)$, recruits' ACS loss $(R l)$, survivors' ACS growth $(S g)$, or survivors' ACS loss $(S l)$.

Survivors Survivors' cumulative ACS changes are null at $t=0$ and have a finite limit, attained once survivors have all died. We modeled survivors' cumulative ACS growth cSg as:

$$
c S g_{j, p, k} \sim \mathcal{N}\left(\alpha_{p}^{S g} \times\left(1-\exp \left(-\beta_{j, k}^{S g} \times t_{k}\right)\right),\left(\sigma^{S g}\right)^{2}\right)
$$

where $j$ is the subplot, $p$ the plot it belongs to, $t_{k}$ is the time since $t_{0} \cdot \alpha_{p}^{S g}$ is the finite limit of the cumulative ACS change, $\beta_{j, k}^{S g}$ the rate at which the cumulative ACS change converges to this limit and $\left(\sigma^{S g}\right)^{2}$ the variance of the model. By choosing an exponential kernel, we assume that survivors' ACS growth at $t_{k}$ is proportional to survivors' ACS growth at $t_{k-1}$.

Because of our nested design with subplots $j$ within plots $p$, we modeled the $\alpha_{p}^{S g}$ values with a random plot effect of mean $\alpha_{0}^{S g}$ and variance $\left(\sigma_{\alpha}^{S g}\right)^{2}$ :

$$
\alpha_{p}^{S g} \sim \mathcal{N}\left(\alpha_{0}^{S g},\left(\sigma_{\alpha}^{S g}\right)^{2}\right)
$$

Parameter $\beta_{j, k}^{S g}$ is the rate at which survivors' ACS growth on plot $j$ at time $t_{k}$ converges to a finite limit after the disturbance: it reflects the response rapidity of survivors' ACS growth to disturbance. Because we are interested in predicting variations in $\beta_{j, k}^{S g}$, we expressed the latter as a function of covariates:

$$
\beta_{j, k}^{S g}=\beta_{0}^{S g}+\sum_{l=1}^{13}\left(\lambda_{l}^{S g} \times V_{j, t_{k}, l}\right)
$$

with $\beta_{0}^{S g}$ the model intercept, $\lambda_{l}^{S g}$ the vector of $l$ parameters associated to the covariates $V_{j, k, l}$ for which we looked at their effects on the post-logging rate $\beta_{j, k}^{S g}$ in subplot $j$ at time $t_{k}$. The covariates are defined above and related to the disturbance intensity DIST, the structure of the forest before disturbance $\left(S_{N}, S_{D G}, S_{B A}\right)$, the functional trait composition of the forest before disturbance $\left(T_{S E E D}, T_{S L A}\right.$, $\left.T_{W D}, T_{D B H 95}\right)$, the local environment $\left(E_{B O T T O M}, E_{S L O P E}\right.$, $\left.E_{H E T E}\right)$ and the climate stress $\left(C_{D R O U G H T}, C_{W A T E R}\right)$. Note that values of the two later covariates changed with times. All covariates are centered and standardized before the inference. When all survivors in plot $p$ are dead, all the $\mathrm{C}$ gained by their growth $\left(c S g_{j, p, \infty}=\alpha_{p}^{S g}\right)$ plus their initial ACS $\left(\operatorname{acsmin}_{j}\right)$ will have been lost $\left(c S l_{j, \infty}=\alpha_{j}^{S l}\right)$. We thus defined

$$
\alpha_{j}^{S l}=\alpha_{p}^{S g}+\operatorname{acsmin}_{j}
$$

with $\alpha_{p}^{S g}, \alpha_{j}^{S l}$ the finite limits of survivors' cumulative ACS growth and ACS loss respectively, and acsmin $j$ the ACS of the subplot $j$ at $t_{\min }=t_{0}$. Then the cumulative carbon loss is

$$
c S l_{j, p, k} \sim \mathcal{N}\left(\alpha_{j}^{S l} \times\left(1-\exp \left(-\beta_{j, t}^{S l} \times t_{k}\right)\right),\left(\sigma^{S l}\right)^{2}\right)
$$

where $j$ is the subplot, $p$ the plot it belongs to, $t_{k}$ is the time since $t_{0} . \alpha_{j}^{S l}$ is the finite limit of the cumulative ACS change, $\beta_{j, k}^{S l}$ the rate at which the cumulative ACS change converges to this limit and $\left(\sigma^{S l}\right)^{2}$ the variance of the model. And with

$$
\beta_{j, t}^{S l}=\beta_{0}^{S l}+\sum_{l=1}^{6}\left(\lambda_{l}^{S l} \times V_{j, t, l}\right)
$$


with $\beta_{0}^{S l}$ the model intercept, $\lambda_{l}^{S l}$ the vector of $l$ parameters associated to the covariates $V_{j, k, l}$ for which we looked at their effects on the post-logging rate $\beta_{j, k}^{S l}$ in subplot $j$ at time $t_{k}$.

Recruits When survivors are all dead, newcomers or recruits will constitute the new forest. We made the assumption that the recruits' annual ACS changes will converge to constant values, with ACS gains compensating ACS losses. Because there are no recruits yet at $t_{0}$, recruits' annual ACS growth $(R g)$ and ACS loss $(R l)$ are zero, and progressively increase to reach their asymptotic values. Recruits' annual ACS growth and ACS loss can be modeled with the function:

$$
f(t ; \alpha, \beta)=\alpha \times(1-\exp (-\beta \times t))
$$

where $t$ the time since the beginning of the recovery period. In the same logic as survivors' cumulative ACS changes, $\alpha$ is the asymptotic value of recruits' annual ACS change $\left(\mathrm{MgC}^{\mathrm{Cg}} \cdot \mathrm{ha}^{-1} \cdot \mathrm{yr}^{-1}\right)$, and $\beta$ is the rate at which this asymptotic value is reached. Contrary to recruits' annual ACS growth and ACS loss, the ACS of new recruits $(R r$, the ACS of tree reaching the $10 \mathrm{~cm} \mathrm{DBH}$ threshold) is high at $t_{0}$ because of the competition drop induced by logging, but then progressively decreases to reach its asymptotic value. We modeled it with the following function:

$$
f(t ; \alpha, \beta)=\alpha \times(1+\exp (-\beta \times t))
$$

where $t$ is the time since disturbance. As stated before, we chose to model cumulative ACS changes instead of annual ACS changes. The general model for recruits' cumulative ACS changes (ACS growth $R g$, ACS loss $R l$ and ACS of new recruits $R r$ ) is obtained by mathematical integrating from $t_{0}$ to $t_{k}$ annual ACS changes:

$c R_{j, p, k} \sim \mathcal{N}\left(\alpha_{p}^{R} \times\left(t_{k}+\eta \times \frac{1-\exp \left(-\beta_{j, k}^{R} \times t_{k}\right)}{\beta_{j, k}^{R}}\right),\left(\sigma^{R}\right)^{2}\right)$

where $j$ is the subplot, $p$ the plot, $t_{k}$ is the time since $t_{0}, R$ is the annual ACS change, either $R r, R g$ or $R l$ and $\left(\sigma^{R}\right)^{2}$ the variance of the model. When $R$ is $R g$ or $R l, \eta=-1$; when $R$ is $R r, \eta=1$. Because of our nested design with subplots $j$ within plots $p$, we modeled the $\alpha_{p}^{R}$ values with a random plot effect of mean $\alpha_{0}^{R}$ and variance $\left(\sigma_{\alpha}^{R}\right)^{2}$ :

$$
\alpha_{p}^{R} \sim \mathcal{N}\left(\alpha_{0}^{R} ;\left(\sigma_{\alpha}^{R}\right)^{2}\right)
$$

When the dynamic equilibrium is reached, annual ACS gain (growth and recruitment) compensates annual ACS loss (mortality). We thus added the following constraint for every plot $p$ :

$$
\alpha_{p}^{R r}+\alpha_{p}^{R g}+\alpha_{p}^{R l}=0
$$

Using the same logic as for survivors, we are interested in predicting variation in $\beta^{R}$ as follows:

$$
\beta_{j, k}^{R} \sim \mathcal{N}\left(\beta_{0}^{R}+\sum_{l=1}^{6}\left(\lambda_{l}^{R} \times V_{j, k, l}\right),\left(\sigma_{\beta}^{R}\right)^{2}\right)
$$

with $R$ being $R g, R l$ or $R r$ depending on the process we were interested in, with $\beta_{0}^{R}$ the model intercept, $\lambda_{l}^{R}$ the vector of $l$ parameters associated to the covariates $V_{j, k, l}$ for which we looked at their effects on the post-logging rate $\beta_{j, k}^{R}$ in subplot $j$ at time $t_{k}$.

\section{Model inference}

Bayesian hierarchical models were inferred through MCMC methods using an adaptive form of the Hamiltonian Monte Carlo sampling (Carpenter et al. 2017). Codes were developed using the $\mathrm{R}$ language and the Rstan package (Carpenter et al. 2017). A detailed list of priors is provided in Table 2.

\section{Identifying the key drivers of the post-disturbance system recovery}

To assess the importance of the pre- (forest structure, environment and composition) and post- (climate stress) disturbance forest conditions, we simulated different scenarios modifying the covariate values but keeping an averaged (set to 0 ) disturbance intensity DIST. Note that all model covariates $V_{j, t, l}$ were standardized before modeling so that, for a given covariate, a $-2,0$ or 2 value respectively refers to a very low, average or very high observed value.

Forest structure The effects of a regenerating (high stem density $S_{N}=1$, low basal area $S_{B A}=-1$ ), intermediate (medium stem density $S_{N}=0$, medium basal area $S_{B A}=$ 0 ) and mature (low stem density $S_{N}=-1$, high basal area $\left.S_{B A}=1\right)$ pre-disturbance forest structure on ecosystem recovery were compared.

Forest environment The effect of three contrasted forest environment were compared: predominance of bottomlands (high proportion of bottom-lands $E_{\text {ВОтTОM }}=2$, medium slope values $E_{S L O P E}=0$, medium altitudinal heterogeneity $E_{H E T E}=0$ ), predominance of slopes (medium proportion of bottom-lands $E_{B O T T O M}=0$, high slope values $E_{S L O P E}=2$, medium altitudinal heterogeneity $E_{H E T E}=0$ ) and hilly landscapes (medium proportion of bottom-lands $E_{\text {ВOTTOM }}=0$, medium slope values $E_{S L O P E}=0$, high altitudinal heterogeneity $E_{H E T E}=2$ ).

Forest composition The effect of pre-logging forest community dominated by conservative tree species (high wood density $T_{W D}=2$, high seed mass $T_{S E E D}=2$, low specific leaf area $T_{S L A}=-2$, high maximal stature 
Table 2 List of priors used to infer ACS changes in a Bayesian framework

\begin{tabular}{llll}
\hline Model & Parameter & Prior & Justification \\
\hline$S g$ & $\alpha_{p}^{S g}$ & $\mathcal{U}(10,200)$ & Around 100 survivors/ha storing 0.1 to $2.0 \mathrm{MgC}$ each \\
$S g$ & $\beta_{j, t}^{S g}$ & $\mathcal{U}(0,0.25)$ & $12<t_{0.95}^{S g}{ }^{*}<+\infty$ \\
$S l$ & $\beta_{j, t}^{S l}$ & $\mathcal{U}\left(0, \beta_{j, t}^{S g}\right)$ & $t_{0.95}^{S g}<t_{0.95}^{S l}{ }^{*}<+\infty$ \\
$R r$ & $\alpha_{p}^{R r}$ & $\mathcal{U}(0.1,1)$ & TmFO observed values (Piponiot et al. 2016b) \\
$R r$ & $\beta_{j, t}^{R r}$ & $\mathcal{U}(0,0.75)$ & $4<t_{0.95}^{R r}{ }^{*}<+\infty$ \\
$R r$ & $\alpha_{p}^{R g}$ & $\mathcal{U}(0.1,3)$ & Amazonian values (Johnson et al. 2016) \\
$R r$ & $\beta_{j, t}^{R g}$ & $\mathcal{U}(0,0.5)$ & $6<t_{0.95}^{R g}{ }^{*}<+\infty$ \\
$R r$ & $\beta_{j, t}^{R l}$ & $\mathcal{U}(0,0.5)$ & $6<t_{0.95}^{R l}<+\infty$ \\
All models $M^{* *}$ & $\lambda_{l}^{M}$ & $\mathcal{U}\left(-\beta_{j, t}^{M}, \beta_{j, t}^{M}\right)$ & avoid multicollinearity problems
\end{tabular}

Models are: (Sg) survivors' ACS growth, (SI) survivors' ACS loss, (Rr) new recruits' ACS, (Rg) recruits' ACS growth, (RI) recruits' ACS loss

${ }^{*} t_{0.95}$ is the time when the ACS change has reached $95 \%$ of its asymptotic value

${ }^{* *} M$ is one of the five models, either $S g, S l, R r, R g$ or $R l$

$T_{D B H 95}=2$ ), by a disturbed community (low wood density $T_{W D}=-2$, low seed mass $T_{S E E D}=-2$, high specific leaf area $T_{S L A}=2$, low maximal stature $T_{D B H 95}=-2$ ) and by a true pioneer community (very low wood density $T_{W D}=-4$, very low seed mass $T_{S E E D}=-4$, very high specific leaf area $T_{S L A}=4$, very low maximal stature $T_{D B H 95}=-4$ ). The values of the last scenario may appear extreme but note that the model was calibrated with mature forest stands only so that covariate values have to be set out of the calibration range to get a true pioneer community.

Climate stress The effects of a wetter (nor or a few seasonal drought $C_{D R O U G H T}=-2$, high soil water saturation during the wet season $C_{W E T}=2$ ), a drier (seasonal droughts $C_{D R O U G H T}=1$, medium soil water saturation during the wet season $C_{W E T}=0$ ) and a even drier (heavy seasonal droughts $C_{D R O U G H T}=2$, medium soil water saturation during the wet season $C_{W E T}=0$ ) climate on ecosystem recovery were compared.

\section{Sensitivity analysis}

To assess the sensitivity of the ecosystem recovery process to the pre- (forest structure, environment and composition) and post- (climate stress) disturbance forest conditions, we simulated the model for an average disturbance intensity DIST $=0$ and, for each group of covariates $V_{j, t, l \neq D I S T}$, varying the values within a group of covariate while setting the other covariates to 0 . In a nutshell, for each group of covariates Climate, Composition, Environment and Structure (i) we independently sampled covariate values from $\mathcal{U}(-2 ; 2)$ while the covariates from the 3 other groups are set to 0 , (ii) we ran the model using the sampled covariate values for a set of 100 parameter values drawn from the posterior chains, (iii) we estimated, after 30 years of simulation, the net carbon balance and (iv) we did the procedure 1000 times per group of covariates.
Doing so, the variability of the net carbon balance after 30 years reflects the sensitivity of ecosystem recovery to the varying group of covariates.

\section{Results}

Given that all the covariates were standardized before modeling, the absolute values of their associated parameters give the weight of each variable in shaping the rates $\beta$ at which the ACS changes reach their asymptotic state. Negative covariate values indicate slowing and positive values indicate accelerating rates. The values of the disturbance intensity DIST parameters always ranked among the highest absolute values, with negative values for Survivors' ACSgrowth and Newrecruits'ACS (Fig. 1a, c) and positive ones for the other three cumulative fluxes (Fig. 1b, d, e).

\section{Pre-disturbance forest structure}

The two variables chosen to describe the pre-disturbance forest structure, i.e. basal area $S_{B A}$ and stem density $S_{N}$, have contrasted behaviors. Basically, associated parameters get their highest absolute values for the two growth models, both Survivors' and Recruits' (Fig. 1a and d), while being close to zero for the other three models (Fig. 1b, c, e). Contribution of Survivors' growth to ACS recovery is higher but declines quicker with high pre-disturbance $S_{B A}$ values and low $S_{N}$ values (Fig. 1a). Contribution of Recruits' growth to ACS recovery declines slowly with high $S_{N}$ values (Fig. 1d). Mature forests (high $S_{B A}$, low $S_{N}$ ) thus recovers faster than regenerating ones (Fig. 2). The relative importance of the pre-disturbance forest structure on the variability of ACS recovery rates is low, with 30 to $50 \mathrm{MgC} \cdot \mathrm{ha}^{-1}$ recovered after 30 years (Fig. 6).

\section{Local environment}

Three variables inform on the forest local environment, i.e. altitudinal heterogeneity $E_{H E T E}$, proportion of 


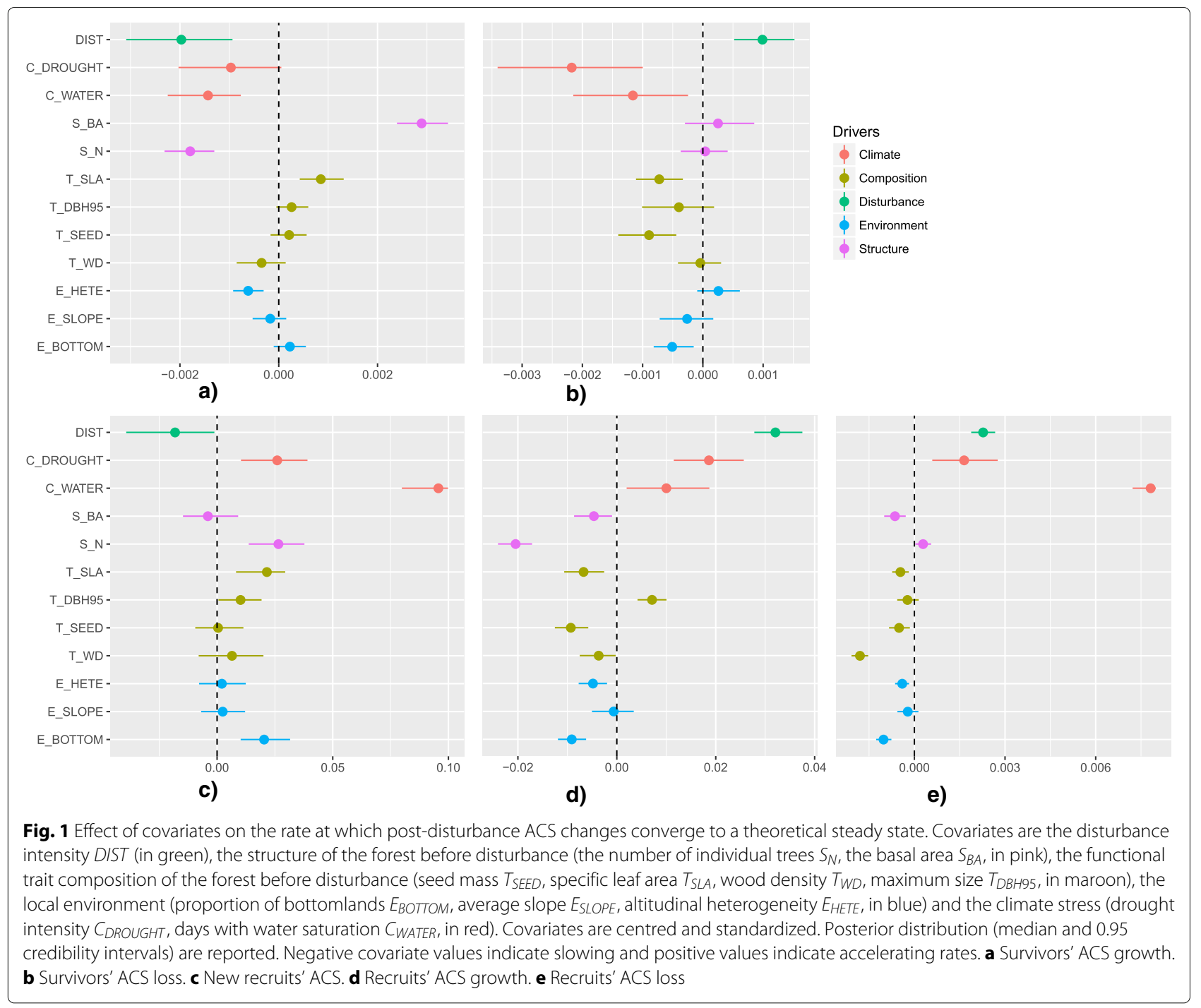

bottomlands $E_{B O T T O M}$ and the average slope $E_{S L O P E}$. The latter never significantly contributes to the $\beta$ variability (Fig. 1). EВОтTOM is important in defining recruits ACS fluxes, with positive parameter values for New recruits' ACS and negative ones for growth and loss (Fig. 1c, d, e). All fluxes together, recovery rates do not differ markedly with environmental conditions (Fig. 3) so that the importance of the local forest environment on the variability of ACS recovery rates is quite low, with 30 to $50 \mathrm{MgC} \cdot \mathrm{ha}^{-1}$ recovered after 30 years (Fig. 6).

\section{Pre-disturbance forest composition}

Four orthogonal functional traits (i.e. specific leaf area $T_{S L A}$, maximum stature $T_{D B H 95}$, seed mass $T_{S L E E D}$ and wood density $T_{W D}$ ) have been retained to summarize differences in pre-disturbance forest composition. All these traits have been found to influence post-disturbance
ACS recovery rates (Fig. 1). For Survivors, the contribution of growth to ACS recovery is higher but declines quicker with high $T_{S L A}$ and low $T_{W D}$ (Fig. 1a) while losses declines slowly with high $T_{S L A}$ and high $T_{S E E D}$ (Fig. 1b). For Recruits, the contribution of growth to ACS recovery is higher but declines quicker with high $T_{D B H 95}$ and low $T_{S L A}$ and $T_{S E E D}$ (Fig. 1d) while losses declines slowly with low $T_{W D}$ (Fig. 1e). Forests, for which the pre-disturbance composition is dominated by conservative ecological strategies (high wood density, seed mass, maximal stature and low specific leaf area) recovers faster than disturbed forests dominated pioneer species (very low wood density, very low seed mass, very high specific leaf area and very low maximal stature) (Fig. 4). The relative importance of the pre-disturbance forest composition on the variability of ACS recovery rates is high, with 0 to $100 \mathrm{MgC} \cdot \mathrm{ha}^{-1}$ recovered after 30 years (Fig. 6). 


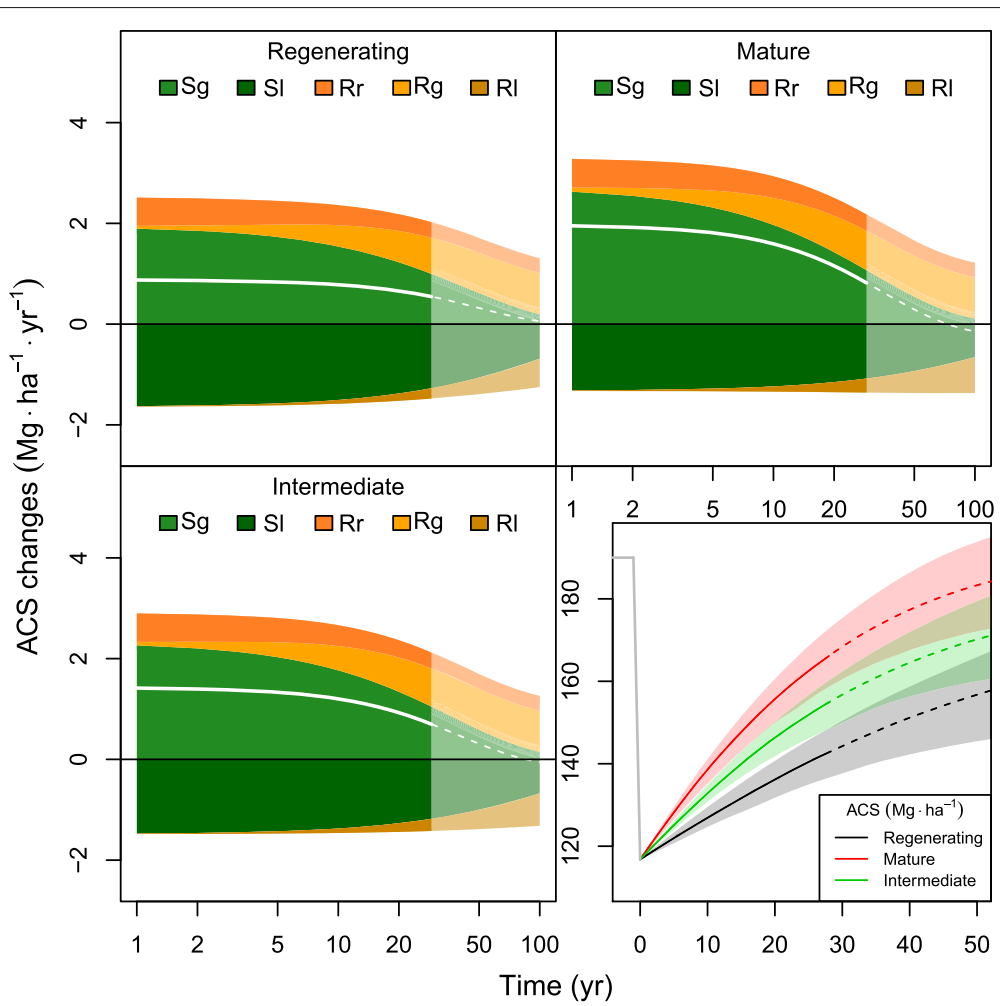

Fig. 2 Predicted contribution of annual ACS changes in three contrasted scenarios of pre-logging forest structure : Regenerating, Mature and Intermediate are defined with standardized covariates $S_{N}$ and $S_{B A}$ respectively set to $[1,-1,0]$ and to $[-1,1,0]$. The white line is the net annual $A C S$ recovery, i.e. the sum of all annual ACS changes: survivors' ACS growth $\mathrm{Sg}$ and loss SI, new recruits' ACS Rr and recruits' ACS growth $R g$ and loss $R /$. Dotted lines are out of the calibration period (0-30 year). Maximum-likelihood predictions for ACS stocks (bottom-right) are projected within their credibility intervals (areas with higher levels of transparency

\section{Post-disturbance climate}

Two variables related to climate stress occurring during the recovery process were tested. The intensity of the dry season $C_{D R O U G H T}$ decelerates the decline of Survivors' ACS changes (Fig. 1a, b) while it accelerates the decline of all the recruits' ACS changes (Fig. 1c, d, e). High soil water saturation during the wet season has a similar effect but with very high $\beta$ values for recruits' ACS loss (Fig. 1e). The forest recovers faster in the driest climate scenarios and this is mainly due to the important Survivors' ACS losses in the wettest scenarios (Fig. 5). The effect of climate stress on the variability of ACS recovery rates ranks 2 nd among the 4 groups of covariates, with 10 to $80 \mathrm{MgC} \cdot \mathrm{ha}^{-1}$, depending on the post-disturbance climate conditions, recovered after 30 years (Fig. 6).

\section{Discussion}

In this study, we modeled the post-disturbance ACS fluxes in a neotropical forest and found that by testing a few variables that are related to the main endogenous (forest structure and composition) and exogeneous (local environment and climate stress) drivers of ecological community dynamics, we could successfully predict ecosystem trajectories in a wide range of preand post-disturbance conditions. Modeling separately the surviving and recruited cohorts was confirmed to be an important methodological choice (Piponiot et al. 2016b), given that the highlighted drivers did not overlap, whether for the growth (Fig. 1a and d) or the loss (Fig. 1b and e) processes. This suggests that our methodological approach, deciphering ecosystem fluxes by demographic processes, could be very useful to predict the long-term trajectories in highly diverse tropical forests for which precise demographic data may be lacking, but aggregative forest dynamic censuses are available from forest inventories. In this study, the disturbance intensity gradient was induced by combining logging to thinning operations (Table 1). Because of its economic value and implications for forest management, selective logging experiments were set up very early on, and the data gathered by these experiments are unique in terms of experiment duration and spatial extent. Despite the particular nature of logging operations (focus on large and commerciallyvaluable trees even though logging damage concerns all DBH classes), we believe that our study gives clues on the key drivers of ecosystem recovery after large ACS losses 


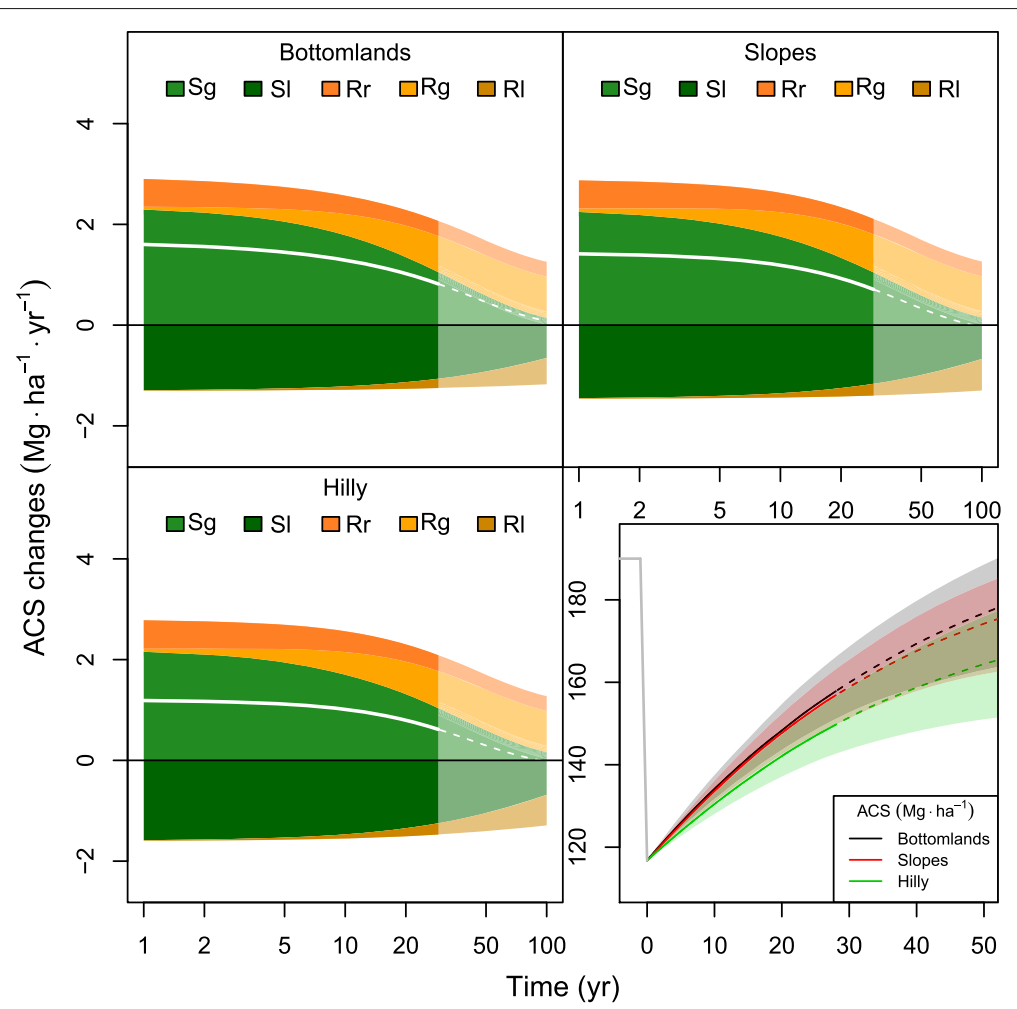

Fig. 3 Predicted contribution of annual ACS changes in three contrasted scenarios of forest environment: Bottomlands, Slopes and Hilly environment are defined with standardized covariates $E_{B O T T O M}, E_{\text {SLOPE }}$ and $E_{\text {HETE }}$ respectively set to $[2,0,0],[0,2,0]$ and $[0,0,2]$. The white line is the net annual ACS recovery, i.e. the sum of all annual ACS changes: survivors' ACS growth Sg and loss SI, new recruits' ACS Rr and recruits' ACS growth $R g$ and loss $R I$. Dotted lines are out of the calibration period (0-30 year). Maximum-likelihood predictions for ACS stocks (bottom-right) are projected within their credibility intervals (areas with higher levels of transparency

induced by other disturbances (e.g. droughts, fire) that are expected to increase in intensity with ongoing global changes (Bonal et al. 2016).

\section{On disturbance intensity}

Disturbance intensity DIST remains, by far, the first predictor of the post-disturbance system trajectory (Fig. 1).

\section{Survivors}

High disturbance intensities obviously reduce the residual survivors' ACS so that ACS changes from survivors' growth is lower at the beginning but, because of the lower competition between survivors, they tend to live longer and reach the asymptotic state slowly (lower $\beta$, Fig. 1a). The positive $\beta$ for Survivors' ACS loss, meaning that survivors tend to die faster after high levels of disturbance, may look surprising because this goes against the growth result. We believe that a high tree mortality, due to the low survival of damaged trees in highly disturbed systems, in the early post-disturbance years may have resulted in increased $\beta$ values. However, those losses should rapidly decrease after a decade (Thorpe et al. 2008).

\section{Recruits}

High disturbance intensities alleviate competition, and this is probably why recruits' ACS growth is high just after disturbance in the enhanced growth conditions (Herault et al. 2010) and then quickly decrease (high $\beta$ s, Fig. 1d and e). In these disturbed forests, intense self-thinning (Feldpausch et al. 2007) may explain the fast but limitedin-times ACS losses from survivors' mortality (Fig. 1e).

\section{Endogeneous drivers}

Pre-disturbance Forest structure All else being equal, mature forests (high $S_{B A}$, low $S_{N}$ ) recover faster than regenerating ones. And this is mainly due to the higher ACS incoming fluxes from Survivors' growth (Fig. 2). Regenerating forests are composed of shortliving fast-growing small species. These species are poorly efficient at carbon accumulation because of their limited growth response to canopy openings and competition alleviation. Indeed, it has been shown in the Paracou forests that species with the highest inherent growth rate (in the absence of disturbance) have the lowest growth response when a disturbance occurs (Herault et al. 2010). On the contrary, large mature trees 


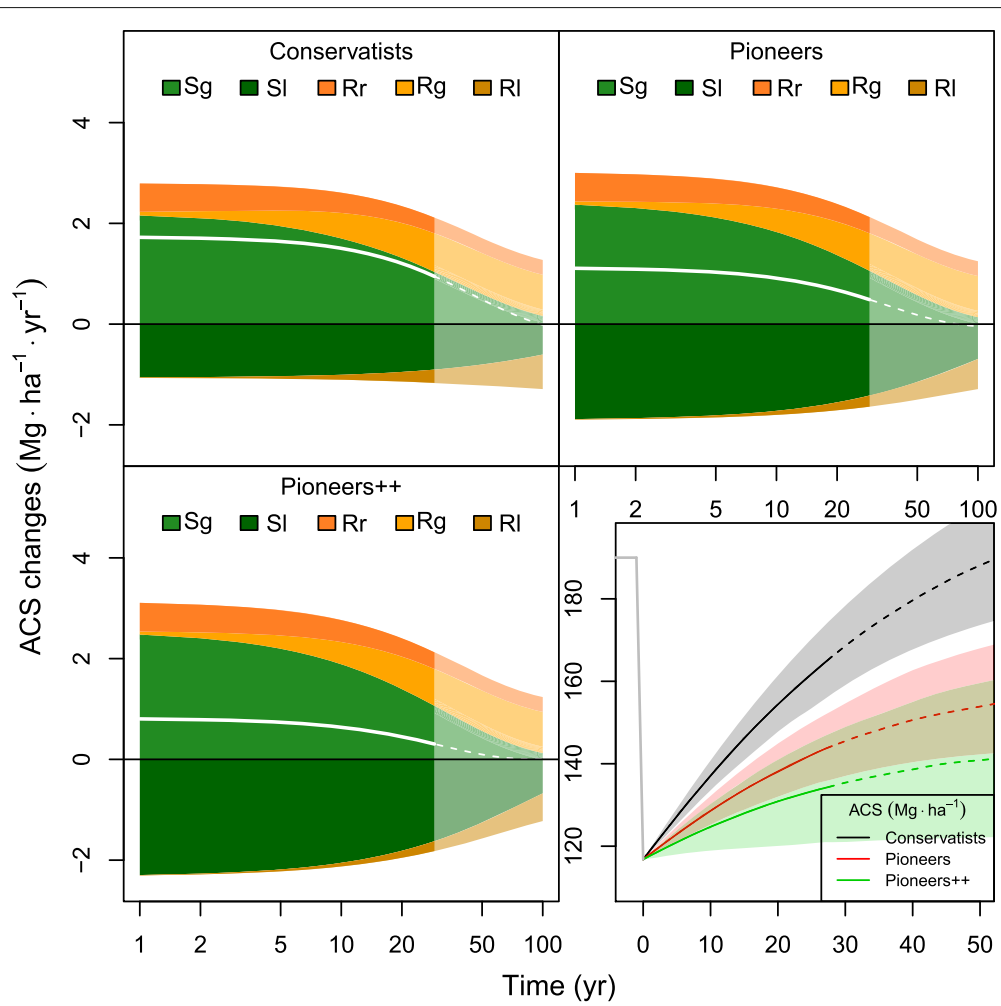

Fig. 4 Predicted contribution of annual ACS changes in three contrasted scenarios of pre-logging forest composition: Conservatists, Pioneers and Pioneers++ communities are defined with standardized covariates $T_{\text {WD, }} T_{\text {SEED }}, T_{\text {SLA }}$ and $T_{\text {DBH95 }}$ respectively set to $[2,-2,-4],[2,-2,-4],[-2,2,4]$ and $[2,-2,-4]$. Pioneers ++ refer to a true pioneer community (very low wood density, very low seed mass, very high specific leaf area and very low maximal stature). The white line is the net annual ACS recovery, i.e. the sum of all annual ACS changes: survivors' ACS growth Sg and loss SI, new recruits' ACS Rr and recruits' ACS growth $R g$ and loss RI. Dotted lines are out of the calibration period (0-30 year). Maximum-likelihood predictions for ACS stocks (bottom-right) are projected within their credibility intervals (areas with higher levels of transparency

are, despite their low numbers in many forests, key elements of carbon storage (Lindenmayer et al. 2012) and dynamics (Sist et al. 2014). Previously disturbed, logged or secondary forests, for which forest structure is characterized by low $S_{B A}$, and high $S_{N}$, may thus be far less resilient to new disturbance than natural undisturbed forests. This also means that post-logging ACS recovery that is currently estimated from the first logging rotation (Rutishauser et al. 2015) may be overestimated for the following logging rotations (Rutishauser et al. 2016). Finally, despite these clear outcomes, the importance of the pre-disturbance forest structure on the variability of ACS recovery rates, as compared to the other covariates (forest composition, environment and climate), remains low (Fig. 6) in the sensitivity analysis. However, we should keep in mind that all the disturbed plots were established in a natural undisturbed forest area so that the model has been parameterized with low pre-disturbance forest structure variability. We thus suggest that, in landscapes with contrasted and tumultuous history, the role of the forest structure in shaping the post-disturbance system trajectory would be much higher.
Pre-disturbance Forest composition The importance of the pre-disturbance forest composition on the variability of the post-disturbance ACS recovery rates is unexpected, with 0 to $100 \mathrm{MgC} \cdot \mathrm{ha}^{-1}$, depending on the initial species assemblage, recovered after 30 years (Fig. 6). All the studied functional traits are implied in shaping one or more of the investigated ACS changes. When comparing two typical forest composition, i.e. an assemblage of conservative trees (high wood density, seed mass, maximal stature and low specific leaf area) and an assemblage of pioneer trees (exact opposite trait composition), the pioneer assemblage recovers much slower. This difference is mainly due to highly contrasted survivors' ACS changes. Both ACS growth and loss increase rapidly in surviving pioneers. This result is consistent with the acquisitive strategy of species with a high carbon budget (Sterck et al. 2011), that are wellknown to have very fast turn-over rates (Aubry-Kientz et al. 2013; Hérault et al. 2011; Flores et al. 2014). Even if both survivors ACS growth and loss are boosted in pioneer assemblages, it is quite remarkable that the ACS balance in time is mainly under the control of survivors' 


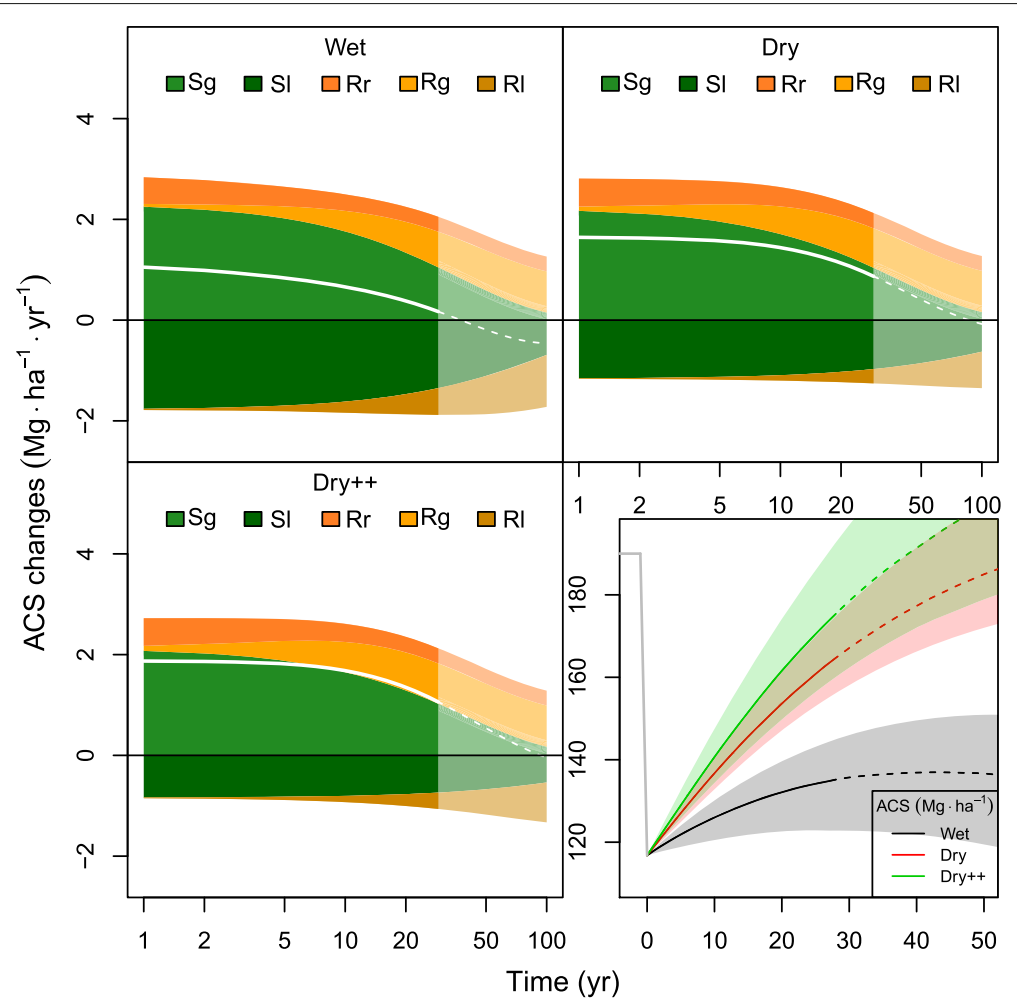

Fig. 5 Predicted contribution of annual ACS changes in three contrasted climate scenarios: Wet, Dry and Dry++ climates are defined with standardized covariates $C_{\text {DROUGHT }}$ and $C_{\text {WATER }}$ respectively set to $[-2,1,2]$ and $[2,0,0]$. Dry++ refer to an extremely-dry climate (very high seasonal drought in the dry season, medium soil water saturation in the rain season). The white line is the net annual ACS recovery, i.e. the sum of all annual ACS changes: survivors' ACS growth Sg and loss Sl, new recruits' ACS Rr and recruits' ACS growth $R g$ and loss Rl. Dotted lines are out of the calibration period (0-30 year). Maximum-likelihood predictions for ACS stocks (bottom-right) are projected within their credibility intervals (areas with higher levels of transparency

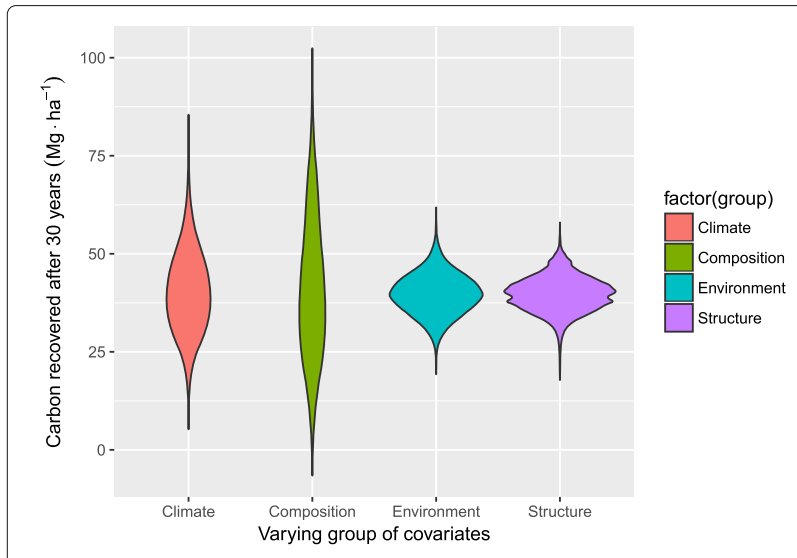

Fig. 6 Estimating the relative importance of the Climate stress, the pre-disturbance forest Composition, Environment and Structure in driving ecosystem recovery 30 years after disturbance. The violin plots represent the variability of the distribution of the net carbon balance when covariates within a given group are independently and randomly drawn from $\mathcal{U}(-2 ; 2)$ while the covariates from other groups are set to 0 (the longest the boxplot the highest the sensitivity of ecosystem recovery to this given group of covariates)
ACS loss Sl. Survivors' ACS loss can cancel survivors' ACS growth in pioneer-dominated communities, resulting in a null ACS balance (zero is included in the simulations results, see Fig. 6). Why do those pre-disturbance pioneer communities have such high ACS losses in the post-disturbance times? Fast-growing pioneers are generally both poor competitors and poor stress-tolerant trees (He et al. 2013). A first possible explanation is thus that the stress induced by disturbance may be too high for these species that undergo, after disturbance, heavy losses. An alternative explanation is that the higher ACS growth mechanically induces, after a while, higher ACS losses. If pioneers grow faster as a result of growth-stimulating disturbance, they will pass through their natural life span faster, resulting in a transitory gain in carbon storage followed by a massive carbon release when these pioneers get older (Körner 2017). Introducing a time lag for the ACS loss models would be the only way to test the last hypothesis.

\section{Exogeneous drivers}

Local environment The forest local environment defined by the altitudinal heterogeneity, the proportion of 
bottomlands and the average slope, have been found to be of low importance in shaping variability of ACS recovery rates (Fig. 3). This result is quite surprising, given that the local environment is very often referred to as a driver of ecological processes in tropical forests (Grau et al. 2017), from fine pairwise interactions between individual trees (Kraft et al. 2008) to regional variation in community assemblages (Fayad et al. 2016). For instance, in the Paracou forest, the proportion of bottomlands have been found to be of primary importance for forest dynamics: treefall rates are twice as high as on hilltops and tree recruitment and growth rates are higher, leading to a lower basal area and ACS (Ferry et al. 2010). Nearly three fourths of the Paracou taxa are locally distributed as a function of relative elevation, with seasonally inundated bottomlands and well-drained plateaus revealing contrasted species associations (Allié et al. 2015). Despite the relative importance of $E_{B O T T O M}$ in defining recruits' ACS changes, with positive $\beta$ parameter values for new recruits' ACS and negative ones for recruits' ACS growth and loss (Fig. 1), all in all ACS recovery rates differ very little from hilly or sloppy plots (Fig. 3). On the one hand, the low-stress conditions of bottomlands (no seasonal drought, less wind) should induce a faster ecosystem recovery. On the other hand, the lower final ACS (Ferry et al. 2010) may mechanically lead to lower absolute carbon storage during recovery. All together, the two processes could be canceling each other, explaining why absolute carbon recovery is similar between bottomlands and hilltops. We also should keep in mind that the disturbance experiment was made by logging. During logging operations, bottomlands are avoided and logging is preferentially conducted in easier-to-access hilltop areas, whatever their proportion in the plot. This may have artificially reduced the environmental difference between logged plots and, in turn, the ACS recovery trajectories.

Post-disturbance climate stress Two seasonal climate stresses were studied: soil water saturation in the wet season and drought intensity in the dry season. The importance of the post-disturbance climate stress on the variability of ACS recovery rates was very high with, depending on the climate scenarios, 10 to $80 \mathrm{MgC} \cdot \mathrm{ha}^{-1}$ recovered after 30 years (Fig. 6). The 2 driest scenarios recover initial ACS very quickly, i.e. in less than 60 years while the wettest one would reach a new asymptotic values, far below the initial system ACS (Fig. 6). The main difference between the 3 scenarios lies in the absolute values of the Survivors' ACS loss, with very high values for the wet scenario. This result may look strange given that drought has often been identified as one of the main climate drivers of tropical forest dynamics (Bonal et al. 2016; Wagner et al. 2012, 2013, 2014, 2016), with large mortality events among tropical trees during
El Nino years for instance (Phillips et al. 2009) that have not only immediate but also long-term and cumulative impacts on the carbon cycle (Doughty et al. 2015). Those large mortality events are associated with tree hydraulic traits, the most susceptible species being those having a low hydraulic safety margin (Anderegg et al. 2016). In this context, why do the most intense dry season generate the lowest carbon losses? In our training dataset, the natural variability of the total rainfall from 2700 to $3100 \mathrm{~mm} \cdot \mathrm{yr}^{-1}$ is quite low and, moreover, is far above the $1500 \mathrm{~mm} \cdot \mathrm{yr}^{-1}$, the evapotranspiration threshold. This means that our experimental forest, located in the Guiana Shield, is not water-limited at all (Stahl et al. 2013), just like the Northern part of the Amazonian basin (Wagner et al. 2017). One may also expect that, because of hydraulic failure, standing death is more frequent during the driest years but, when plotting the tree mode of death registered at Paracou for each dead tree against the drought estimator, no evidence was observed for a potential trend (Aubry-Kientz et al. 2015). Our results thus reinforce the idea that the dominant seasonal climate stress in the Paracou forest is not drought during dry season but water saturation during wet season. This confirms the hypothesis that waterlogged soils in space or in time are risky for trees (Ferry et al. 2010). Moreover, during the rainy season, strong rainfall events often come with strong winds that may reinforce ACS losses (Toledo et al. 2011) and we know, from the Paracou dataset, that the highest total precipitation leads to the highest proportion of tree-fall deaths (Aubry-Kientz et al. 2015). Global climate models converge to simulate, at least for the Amazonian region, a change in precipitation regime over the coming decades (Malhi et al. 2009). Seasonal droughts are expected to become longer and stronger in the future (Joetzjer et al. 2013). Our simulations would suggest that post-disturbance forest recovery would be faster with these new climate conditions. However, we should keep in mind that our simulations were based on a model calibrated with data from a natural, undisturbed forest (Fargeon et al. 2016). With increasing mortality rates due to increasing drought occurrence and severity, the new tree community may be richer in post-disturbance pioneer species. And we have already seen that these new assemblages will slowly recover (Fig. 4) so that recurrent climate-stress in time would not lead to faster recovery rates, but rather to pioneer-rich forest communities with slow recovery rates.

\section{Conclusion}

More than half of the tropical forest area are currently designated by National Forests Services as production forests (Blaser et al. 2011) and they consequently play a key role in the tropical forest carbon balance 
(Piponiot et al. 2016a; Sist et al. 2015). In the Amazon, forest logging and degradation combined to climate change would render up to $80 \%$ of the forest area susceptible to major disturbance events in the coming decades (Asner et al. 2010). We have shown that the pre-disturbance forest composition and the post-disturbance climate conditions are of primary importance to predict the recovery potential of tropical forest ecosystems. From the Paracou long-term experiment, it becomes increasingly clear that highly-disturbed forests, because they contain a lot of pioneer species (Baraloto et al. 2012), will be less able to cope with (i) new disturbance such as logging and (ii) the drier conditions induced by climate change. In other words, already-disturbed forests are likely to be the most vulnerable systems in the current global change context. Forest managers should thus (i) encourage the development of Reduced-Impact Logging techniques in order to minimize disturbance intensity and (ii) pay a deep attention when drawing management plans to avoid logging pioneer-rich forest units. In the context of increasing disturbances on tropical forests, the lower capacity of disturbed forests to recover is not good news in our fight against climate change.

\section{Acknowledgements}

We are in debt with all technicians and colleagues who helped setting up the plots and collecting data over years. Without their precious work, this study would have not been possible and they may be warmly thanked here.

\section{Funding}

This study was funded by (i) the GFclim project (FEDER 2014-2020, Project GY0006894) and (ii) an Investissement d'avenir grant of the ANR (CEBA: ANR-10-LABEX-0025).

\section{Availability of data and materials}

Datasets supporting the conclusions of this article are available upon request to the scientific director of the Paracou Station (https://paracou.cirad.fr).

\section{Authors' contributions}

$\mathrm{BH}$ and $\mathrm{CP}$ drew the concept of the paper, developed the modeling mathematical framework and worked on the parametrization of the model. BH worked on the first draft and both authors improved and approved the final manuscript.

\section{Authors' information}

$\mathrm{BH}$ is an ecological modeler at Cirad (French research institute specialized in development-oriented research for the tropics). He was the scientific coordinator of the Paracou Research Station from 2012 to 2017. He is currently welcomed by Institut National Polytechnique Félix Houphouët-Boigny, Ivory Coast, to develop researches on forest restoration in West Africa. CP is a recent forest engineer from France. She is a PhD candidate at the Joint Research Unit 'Ecology of French Guianan Forests' - Université de Guyane. She is currently working on modeling the recovery of ecosystem services in disturbed amazonian forests under the Tropical Managed Forest Observatory (http://www.tmfo.org) framework.

\section{Ethics approval and consent to participate}

Not applicable.

\section{Consent for publication}

Not applicable.

\section{Competing interests}

The authors declare that they have no competing interests.

\section{Author details}

${ }^{1}$ Cirad, UMR EcoFoG (AgroParistech, CNRS, Inra, Université des Antilles, Université de la Guyane), Campus Agronomique, 97310 Kourou, French Guiana, France. ${ }^{2}$ INPHB (Institut National Polytechnique Félix Houphouët Boigny), Yamoussoukro, Ivory Coast. ${ }^{3}$ Université de la Guyane, UMR EcoFoG (AgroParistech, Cirad, CNRS, Inra, Université des Antilles), Campus

Agronomique, 97310 Kourou, French Guiana, France.

Received: 9 July 2017 Accepted: 20 December 2017

Published online: 09 February 2018

\section{References}

Allié E, Pélissier R, Engel J, Petronelli P, Freycon V, Deblauwe V, Soucémarianadin L, Weigel J, Baraloto C (2015) Pervasive Local-Scale Tree-Soil Habitat Association in a Tropical Forest Community. Plos ONE 10(11):e0141488

Anderegg WRL, Klein T, Bartlett M, Sack L, Pellegrini AFA, Choat B, Jansen S (2016) Meta-analysis reveals that hydraulic traits explain cross-species patterns of drought-induced tree mortality across the globe. Proc Natl Acad Sci 113(18):201525678

Asner GP, Loarie SR, Heyder U (2010) Combined effects of climate and land-use change on the future of humid tropical forests. Conserv Lett 3(6):395-403

Aubry-Kientz M, Hérault B, Ayotte-Trépanier C, Baraloto C, Rossi V (2013) Toward trait-based mortality models for tropical forests. PloS one 8(5):e63678

Aubry-Kientz M, Rossi V, Wagner F, Hérault B (2015) Identifying climatic drivers of tropical forest dynamics. Biogeosciences 12(19):5583-5596

Baraloto C, Hérault B, Paine CET, Massot H, Blanc L, Bonal D, Molino J-F, Nicolini Ea, Sabatier D (2012) Contrasting taxonomic and functional responses of a tropical tree community to selective logging. J Appl Ecol 49(4):861-870

Baraloto C, Timothy Paine CE, Poorter L, Beauchene J, Bonal D, Domenach A-M Hérault B, Patiño S, Roggy J-C, Chave J (2010) Decoupled leaf and stem economics in rain forest trees. Ecol Lett 13(11):1338-47

Blanc L, Echard M, Herault B, Bonal D, Marcon E, Chave J, Baraloto C (2009) Dynamics of aboveground carbon stocks in a selectively logged tropical forest. Ecol Appl 19(6):1397-1404

Blaser J, Sarre A, Poore D, Johnson S (2011) Status of Tropical Forest Management 2011. ITTO Technical Series No 38. International Tropical Timber Organization. Yokohama, Japan

Bonal D, Burban B, Stahl C, Wagner F, Hérault B (2016) The response of tropical rainforests to drought-lessons from recent research and future prospects. Ann For Sci 73(1):27-44

Brienen RJW, Phillips OL, Feldpausch TR, et al. (2015) Long-term decline of the Amazon carbon sink. Nature 519(7543):344-348

Brokaw N, Busing R (2000) Niche versus chance and tree diversity in forest gaps. Trends Ecol Evol 15(5):183-188

Carpenter B, Gelman A, Hoffman MD, Lee D, Goodrich B, Betancourt M, Brubaker M, Guo J, Li P, Riddell A (2017) Stan : A Probabilistic Programming Language. J Stat Softw 76(1). doi:10.18637/jss.v076.i01

Chave J, Coomes D, Jansen S, Lewis SL, Swenson NG, Zanne AE (2009) Towards a worldwide wood economics spectrum. Ecol Lett 12(4):351-366

Condit R (1995) Research in large, long-term tropical forest plots. Trends Ecol Evol 10(1):18-22

Davidson Ea, de Araújo AC, Artaxo P, Balch JK, Brown IF, C Bustamante MM Coe MT, DeFries RS, Keller M, Longo M, Munger JW, Schroeder W, Soares-Filho BS, Souza CM, Wofsy SC (2012) The Amazon basin in transition. Nature 481(7381):321-8

Denslow JS, Ellison AM, Sanford RE (1998) Treefall gap size effects on aboveand below-ground processes in a tropical wet forest. J Ecol 86(4):597-609

Dezécache C, Faure E, Gond V, Salles J-M, Vieilledent G, Hérault B (2017a) Gold-Rush in a forested El Dorado: Deforestation leakages and the need for regional cooperation. Environ Res Lett 034013:19

Dezécache C, Salles JM, Vieilledent G, Hérault B (2017b) Moving forward socio-economically focused models of deforestation. Glob Chang Biol 23(9):3484-3500

Doughty CE, Metcalfe DB, Girardin CAJ, Amézquita FF, Cabrera DG, Huasco WH, Silva-Espejo JE, Araujo-Murakami A, da Costa MC, Rocha W, Feldpausch TR, Mendoza ALM, da Costa ACL, Meir P, Phillips OL, Malhi Y (2015) Drought 
impact on forest carbon dynamics and fluxes in Amazonia. Nature 519(7541):78-82

Fargeon H, Aubry-kientz M, Brunaux O, Descroix L, Guitet S, Rossi V, Hérault B (2016) Vulnerability of commercial tree species to water stress in logged forests of the Guiana shield. Forests 7(105):1-21

Fayad I, Baghdadi N, Guitet S, Bailly J-S, Hérault B, Gond V, El Hajj M, Tong Minh DH (2016) Aboveground biomass mapping in French Guiana by combining remote sensing, forest inventories and environmental data. Int J Appl Earth Obs Geoinformation 52(August):502-514

Feeley KJ, Joseph Wright S, Nur Supardi MN, Kassim AR, Davies SJ (2007) Decelerating growth in tropical forest trees. Ecol Lett 10(6):461-9

Feldpausch TR, Prates-Clark CdC, Fernandes EC, Riha SJ (2007) Secondary forest growth deviation from chronosequence predictions in central Amazonia. Glob Chang Biol 13(5):967-979

Ferry B, Bontemps J-d, Blanc L, Freycon V, Nancy E, Nancy F (2010) Higher treefall rates on slopes and waterlogged soils result in lower stand biomass and productivity in a tropical rain forest. J Ecol 98:106-116

Flores O, Hérault B, Delcamp M, Garnier E, Gourlet-Fleury S (2014) Functional traits help predict post-disturbance demography of tropical trees. PloS one 9(9):e105022

Goulamoussène Y, Bedeau C, Descroix L, Deblauwe V, Linguet L, Hérault B (2016) Weak Environmental Controls of Tropical Forest Canopy Height in the Guiana Shield. Remote Sens 8:747

Goulamoussène Y, Bedeau C, Descroix L, Linguet L, Hérault B (2017) Environmental control of natural gap size distribution in tropical forests. Biogeosciences 14(2):353-364

Grau O, Peñuelas J, Ferry B, Freycon V, Blanc L, Desprez M, Baraloto C, Chave J, Descroix L, Dourdain A, Guitet S, Janssens IA, Sardans J, Hérault B (2017) Nutrient-cycling mechanisms other than the direct absorption from soil may control forest structure and dynamics in poor Amazonian soils. Sci Rep 7(February):45017

Guitet S, Hérault B, Molto Q, Brunaux O, Couteron P (2015) Spatial Structure of Above-Ground Biomass Limits Accuracy of Carbon Mapping in Rainforest but Large Scale Forest Inventories Can Help to Overcome. PLoS ONE 10(9):e0138456

Guitet S, Sabatier D, Brunaux O, Hérault B, Aubry-Kientz M, Molino J-F, Baraloto C (2014) Estimating tropical tree diversity indices from forestry surveys: A method to integrate taxonomic uncertainty. For Ecol Manag 328:270-28

He Q, Bertness MD, Altieri AH (2013) Global shifts towards positive species interactions with increasing environmental stress. Ecol Lett 16(5):695-706

Hérault B, Bachelot B, Poorter L, Rossi V, Bongers F, Chave J, Paine CET, Wagner F, Baraloto C (2011) Functional traits shape ontogenetic growth trajectories of rain forest tree species. J Ecol 99(6):1431-1440

Hérault B, Gourlet-Fleury S (2016) Will Tropical Rainforests Survive Climate Change? In: Torquebiau E (ed). Climate Change and Agriculture Worldwide. Editions Q. Versailles. Springer, France. pp 183-196. doi:10.1007/978-94-017-7462-8_14

Herault B, Ouallet J, Blanc L, Wagner F, Baraloto C (2010) Growth responses of neotropical trees to logging gaps. J Appl Ecol 47(4):821-831

Joetzjer E, Douville H, Delire C, Ciais P (2013) Present-day and future Amazonian precipitation in global climate models: CMIP5 versus CMIP3. Clim Dyn 41(11-12):2921-2936

Johnson MO, Galbraith D, Gloor M, De Deurwaerder H, Guimberteau M, Rammig A, Thonicke K, Verbeeck H, von Randow C, Monteagudo A, Phillips OL, Brienen RJ, Feld pausch TR, Lopez Gonzalez G, Fauset S, Quesada CA, Christoffersen B, Ciais P, Sampaio G, Kruijt B, Meir P, Moorcroft P, Zhang K, Alvarez-Davila E, Alves de Oliveira A, Amaral I, Andrade A, Aragao LE, Araujo-Murakami A, Arets EJ, Arroyo L, Aymard GA, Baraloto C, Barroso J, Bonal D, Boot R, Camargo J, Chave J, Cogollo A, Cornejo Valverde F, Lola da Costa AC, Di Fiore A, Ferreira L, Higuchi N, Honorio EN, Killeen TJ, Laurance SG, Laurance WF, Licona J, Lovejoy T, Malhi Y, Marimon B, Marimon BH, Matos DC, Mendoza C, Neill DA, Pardo G, Peña-Claros M, Pitman NC, Poorter L, Prieto A, Ramirez-Angulo H, Roopsind A, Rudas A, Salomao RP, Silveira M, Stropp J, ter Steege H, Terborgh J, Thomas R, Toledo M, Torres-Lezama A, van der Heijden GM, Vasquez R, Guimã IC, Vilanova E, Vos VA, Baker TR (2016). Variation in stem mortality rates determines patterns of above-ground biomass in Amazonian forests: implications for dynamic global vegetation models. Glob Chang Biol 22(12):3996-4013

Körner C (2017) A matter of tree longevity. Science 355(6321):130-131

Kraft NJB, Valencia R, Ackerly DD (2008) Functional traits and niche-based tree community assembly in an Amazonian forest. Science 322(5901):580-2
Kunstler G, Falster D, Coomes DA, Hui F, Kooyman RM, Laughlin DC, Poorter L, Vanderwel M, Vieilledent G, Wright SJ, Aiba M, Baraloto C, Caspersen J, Cornelissen JHC, Gourlet-Fleury S, Hanewinkel M, Herault B, Kattge J, Kurokawa H, Onoda Y, Peñuelas J, Poorter H, Uriarte M, Richardson S, Ruiz-Benito P, Sun I-F, Ståhl G, Swenson NG, Thompson J, Westerlund B, Wirth C, Zavala MA, Zeng H, Zimmerman JK, Zimmermann NE, Westoby M (2016) Plant functional traits have globally consistent effects on competition. Nature 529(7585):204-207

Liang J, Crowther TW, Picard N, Wiser S, Zhou M, Alberti G, Schulze E-D, McGuire AD, Bozzato F, Pretzsch H, De-Miguel S, Paquette A, Herault B, Scherer-Lorenzen M, Barrett CB, Glick HB, Hengeveld GM, Nabuurs G-J, Pfautsch S, Viana H, Vibrans AC, Ammer C, Schall P, Verbyla D, Tchebakova N, Fischer M, Watson JV, Chen HYH, Lei X, Schelhaas M-J, Lu H, Gianelle D, Parfenova El, Salas C, Lee E, Lee B, Kim HS, Bruelheide H, Coomes DA, Piotto D, Sunderland T, Schmid B, Gourlet-Fleury S, Sonke B, Tavani R, Zhu J, Brandl S, Vayreda J, Kitahara F, Searle EB, Neldner VJ, Ngugi MR, Baraloto C, Frizzera L, Ba azy R, Oleksyn J, Zawi a Niedwiecki T, Bouriaud O, Bussotti F, Finer L, Jaroszewicz B, Jucker T, Valladares F, Jagodzinski AM, Peri PL, Gonmadje C, Marthy W, OBrien T, Martin EH, Marshall AR, Rovero F, Bitariho R, Niklaus PA, Alvarez-Loayza P, Chamuya N, Valencia R, Mortier F, Wortel V, Engone-Obiang NL, Ferreira LV, Odeke DE, Vasquez RM, Lewis SL, Reich PB (2016) Positive biodiversity-productivity relationship predominant in global forests. Science 354(6309):aaf8957-aaf8957

Lindenmayer DB, Laurance WF, Franklin JF (2012) Ecology. Global decline in large old trees. Science 338(6112):1305-6

Malhi Y, Aragao LEOC, Galbraith D, Huntingford C, Fisher R, Zelazowski P, Sitch S, McSweeney C, Meir P (2009) Exploring the likelihood and mechanism of a climate-change-induced dieback of the Amazon rainforest. Proc Natl Acad Sci 106(49):20610-20615

Phillips OL, Aragão LEOC, Lewis SL, Fisher JB, Lloyd J, López-Gonzȧlez G, Malhi Y, Monteagudo A, Peacock J, Quesada CA, van der Heijden G, Almeida S, Amaral I, Arroyo L, Aymard G, Baker TR, Bánki O, Blanc L, Bonal D, Brando P, Chave J, de Oliveira ACA, Cardozo ND, Czimczik CI, Feldpausch TR, Freitas MA, Gloor E, Higuchi N, Jiménez E, Lloyd G, Meir P, Mendoza C, Morel A, Neill DA, Nepstad D, Patiño S, Peñuela MC, Prieto A, Ramirez F, Schwarz M, Silva J, Silveira M, Thomas AS, Steege HT, Stropp J, Vàsquez R, Zelazowski P, Alvarez Dávila E, Andelman S, Andrade A, Chao K-j, Erwin T, Di Fiore A, Honorio CE, Keeling H, Killeen TJ, Laurance WF, Peña Cruz A, Pitman NCA, Núñez Vargas P, Ramirez-Angulo H, Rudas A, Salamáo R, Silva N, Terborgh J, Torres-Lezama A (2009) Drought sensitivity of the Amazon rainforest. Sci (New York, NY) 323(5919):1344-1347

Pillet M, Joetzjer E, Belmin C, Chave J, Ciais P, Dourdain A, Evans M, Hérault B, Luyssaert S, Poulter B (2017) Disentangling competitive vs. climatic drivers of tropical forest mortality. J Ecol 38(1):42-49

Piponiot C, Cabon A, Descroix L, Dourdain A, Mazzei L, Ouliac B, Rutishauser E, Sist P, Hérault B (2016a) A methodological framework to assess the carbon balance of tropical managed forests. Carbon Balance Manag 11(1):15

Piponiot C, Sist P, Mazzei L, Peña-Claros M, Putz FE, Rutishauser E, Shenkin A, Ascarrunz N, de Azevedo CP, Baraloto C, França M, Guedes M, Honorio Coronado EN, D'Oliveira MV, Ruschel AR, da Silva KE, Doff Sotta E, de Souza CR, Vidal E, West TA, Hérault B (2016b) Carbon recovery dynamics following disturbance by selective logging in Amazonian forests. eLife 5:e21394

Réjou-Méchain M, Tanguy A, Piponiot C, Chave J, Hérault B (2017) biomass?: an $r$ package for estimating above-ground biomass and its uncertainty in tropical forests. Methods Ecol Evol 8(9):1163-67. doi:10.1111/2041-210X.12753

Rutishauser E, Hérault B, Baraloto C, Blanc L, Descroix L, Sotta ED, Ferreira J, Kanashiro M, Mazzei L, D'Oliveira MV, de Oliveira LC, Peña-Claros M, Putz FE, Ruschel AR, Rodney K, Roopsind A, Shenkin A, da Silva KE, de Souza CR, Toledo M, Vidal E, West TA, Wortel V, Sist P (2015) Rapid tree carbon stock recovery in managed Amazonian forests. Curr Biol 25(18):R787—R788

Rutishauser E, Hérault B, Petronelli P, Sist P (2016) Tree Height Reduction After Selective Logging in a Tropical Forest. Biotropica 48(3):285-289

Rutishauser E, Wagner F, Herault B, Nicolini E-A, Blanc L (2010) Contrasting above-ground biomass balance in a Neotropical rain forest. J Veg Sci 21(4):672-82. doi:10.1111/j.1654-1103.2010.01175.x

Sheil D, Burslem D (2003) Disturbing hypotheses in tropical forests. Trends Ecol Evol 18(1):5-8

Sist P, Mazzei L, Blanc L, Rutishauser E (2014) Large trees as key elements of carbon storage and dynamics after selective logging in the Eastern Amazon. For Ecol Manag 318:103-109 
Sist P, Rutishauser E, Peña-Claros M, Shenkin A, Hérault B, Blanc L, Baraloto C, Baya F, Benedet F, da Silva KE, Descroix L, Ferreira JN, Gourlet-Fleury S, Guedes MC, Bin Harun I, Jalonen R, Kanashiro M, Krisnawati H, Kshatriya M, Lincoln P, Mazzei L, Medjibé V, Nasi R, D'Oliveira MVN, de Oliveira LC, Picard N, Pietsch S, Pinard M, Priyadi H, Putz FE, Rodney K, Rossi V, Roopsind A, Ruschel AR, Shari NHZ, Rodrigues de Souza C, Susanty FH, Sotta ED, Toledo M, Vidal E, aP West T, Wortel V, Yamada T (2015) The Tropical managed Forests Observatory: a research network addressing the future of tropical logged forests. Appl Veg Sci 18:171-174

Slik JWF (2004) El Niño droughts and their effects on tree species composition and diversity in tropical rain forests. Oecologia 141(1):114-120

Stahl C, Hérault B, Rossi V, Burban B, Bréchet C, Bonal D (2013) Depth of soil water uptake by tropical rainforest trees during dry periods: does tree dimension matter? Oecologia 173(4):1191-201

Sterck F, Markesteijn L, Schieving F, Poorter L (2011) Functional traits determine trade-offs and niches in a tropical forest community. Proc Natl Acad Sci U S A 108(51):20627-32

Tan ZH, Cao M, Yu GR, Tang JW, Deng XB, Song QH, Tang Y, Zheng Z, Liu WJ, Feng ZL, Deng Y, Zhang JL, Liang N, Zhang YP (2013) High sensitivity of a tropical rainforest to water variability: Evidence from 10 years of inventory and eddy flux data. J Geophys Res Atmos 118(16):9393-9400

Thorpe HC, Thomas SC, Caspersen JP (2008) Tree mortality following partial harvests is determned by skidding proximity. Ecol Appl 18(7):1652-1663

Toledo M, Poorter L, Peña-Claros M, Alarcón A, Balcȧzar J, Leaño C, Licona JC, Llanque $\mathrm{O}$, Vroomans V, Zuidema P, Bongers $\mathrm{F}$ (2011) Climate is a stronger driver of tree and forest growth rates than soil and disturbance. J Ecol 99(1):254-264

Wagner F, Herault B, Rossi V, Hilker T, Maeda E, Sanchez A, Lyapustin A, Galyao L, Wang Y, Aragao L (2017) Climate drivers of the Amazon forest greening. PloS ONE 12:e0180932

Wagner F, Hérault B, Stahl C, Bonal D, Rossi V (2011) Modeling water availability for trees in tropical forests. Agric For Meteorol 151(9):1202-1213

Wagner F, Rossi V, Aubry-Kientz M, Bonal D, Dalitz H, Gliniars R, Stahl C, Trabucco A, Hérault B (2014) Pan-tropical analysis of climate effects on seasonal tree growth. PloS ONE 9(3):e92337

Wagner F, Rossi V, Stahl C, Bonal D, Hérault B (2012) Water availability is the main climate driver of neotropical tree growth. PloS ONE 7(4):e34074

Wagner, F, Rossi V, Stahl C, Bonal D, Hérault B (2013) Asynchronism in leaf and wood production in tropical forests: a study combining satellite and ground-based measurements. Biogeosciences 10(11):7307-7321

Wagner FH, Hérault B, Bonal D, Stahl C, Anderson LO, Baker TR, Becker GS, Beeckman H, Boanerges Souza D, Botosso PC, Bowman DMJS, Bräuning A, Brede B, Brown Fl, Camarero JJ, Camargo PB, Cardoso FCG, Carvalho FA, Castro W, Chagas RK, Chave J, Chidumayo EN, Clark DA, Costa FRC, Couralet C, da Silva Mauricio PH, Dalitz H, de Castro VR, de Freitas Milani JE, de Oliveira EC, de Souza Arruda L, Devineau J-L, Drew DM, Dünisch O, Durigan G, Elifuraha E, Fedele M, Ferreira Fedele L, Figueiredo Filho A, Finger CAG, Franco AC, Freitas Júnior JL, Galvão F, Gebrekirstos A, Gliniars R, Graça PMLdA, Griffiths AD, Grogan J, Guan K, Homeier J, Kanieski MR, Kho LK, Koenig J, Kohler SV, Krepkowski J, Lemos-Filho JP, Lieberman D, Lieberman ME, Lisi CS, Longhi Santos T, López Ayala JL, Maeda EE, Malhi Y, Maria VRB, Marques MCM, Marques R, Maza Chamba H, Mbwambo L, Melgaço KLL, Mendivelso HA, Murphy BP, O'Brien JJ, Oberbauer SF, Okada N, Pélissier R, Prior LD, Roig FA, Ross M, Rossatto DR, Rossi V, Rowland L, Rutishauser E, Santana H, Schulze M, Selhorst D, Silva WR, Silveira M, Spannl S, Swaine MD, Toledo JJ, Toledo MM, Toledo M, Toma T, Tomazello Filho M, Valdez Hernández JI, Verbesselt J, Vieira SA, Vincent G, Volkmer de Castilho C, Volland F, Worbes M, Zanon MLB, Aragão LEOC (2016) Climate seasonality limits leaf carbon assimilation and wood productivity in tropical forests. Biogeosciences 13(8):2537-2562

\section{Submit your manuscript to a SpringerOpen ${ }^{\circ}$ journal and benefit from:}

- Convenient online submission

- Rigorous peer review

- Open access: articles freely available online

- High visibility within the field

- Retaining the copyright to your article

Submit your next manuscript at $\boldsymbol{\sim}$ springeropen.com 